Contents lists available at journal2.unusa.ac.id

Environmental and Toxicology Management

journal homepage: www.journal2.unusa.ac.id/etm

\title{
Activated carbon and biochar from pineapple waste biomass for the removal of methylene blue
}

\author{
Khoirun Nisa Mahmuda ${ }^{1}$, Tan Hui Wen², and Zainul Akmar Zakaria ${ }^{2, *}$ \\ ${ }^{1}$ Institute of Bioproduct Development, Universiti Teknologi Malaysia, UTM Johor Bahru, 81310, Johor, Malaysia \\ ${ }^{2}$ Department of Bioprocess Engineering, School of Chemical and Energy Engineering, Universiti Teknologi Malaysia, UTM Johor Bahru, \\ 81310, Johor, Malaysia
}

\begin{abstract}
Dye pollution in water system is of concern due to its carcinogenicity and its effect on aesthetic feature. One pollutant of interest is methylene blue (MB), which is a cationic dye widely used in industries. In this study, pyrolysis process was used to convert pineapple waste biomass (PWB) into useful adsorbents such as biochar (BC) and activated carbon (AC) to remove MB in water. BC was produced from pyrolysis of $\mathrm{PWB}\left(340^{\circ} \mathrm{C}, 3\right.$ hours $)$ whereas $\mathrm{AC}$ was prepared from pyrolysis of $\mathrm{PWB}\left(500^{\circ} \mathrm{C}, 1\right.$ hour $)$ impregnated with zinc chloride ( $\mathrm{ZnCl} 2)$. Prior to use, AC-PWB and BC-PWB were characterized for surface area, functional groups and surface morphology. Removal of $\mathrm{MB}$ was investigated by varying different parameters i.e. initial MB concentration and contact time, adsorbent dosage and temperature. Results obtained showed that AC-PWB has higher adsorption capacity than BC-PWB. The adsorption capacity and adsorption rate increased with increasing initial concentration of $\mathrm{MB}$, adsorbent dosage and temperature until reached equilibrium condition. As a conclusion, PWB can be used as a useful raw material to produce cheap and environmentally friendly adsorbent to remove dye from solution.
\end{abstract}

Keywords :

Pineapple biomass; biochar; activated carbon; $\mathrm{ZnCl} 2$ activation; methylene blue

\section{Introduction}

Pineapple (Ananas comosus) is the first crop grown as a commodity crop in Malaysia (Jaji, et al., 2018). The harvested area was around 15,611 hectares, which produces 21.42 tonnes of pineapple fruits per hectare (Zainuddin, et al., 2014). Due to its distinct flavour, pleasant aroma and delicious taste, pineapple is produced as canned fruits, jams, juices, flavourings and concentrates. The increasing production of pineapple processed items, results in massive waste generations mainly due to selection and elimination of components unsuitable for human consumption (Upadhyay, et al., 2010). About $30-50 \%$ of the total fruit weight is discarded as waste during canning (Lun, et al., 2014). Pineapple waste consists of residual skin, peel, pulps, stem, and leaves which are by-products of the pineapple processing industries. Pyrolysis process in one of the waste management measure to reduce the risks associated with waste disposal and to convert the biomass into value added products such as biochar, bio-oil, pyroligneous acid, and gaseous product (Tripathi, et al., 2016). Activated carbon are produced by pyrolysis (to produce pyrogenic carbonaceous materials i.e. biochar) and further activation by chemical or physical method (Sharath, et al., 2017, Ahmida, et al., 2015).

\footnotetext{
* Corresponding Author.

Email Address : zainulakmar@utm.my https://doi.org/10.33086/etm.vli1.2036 Received from 30 March 2021;

Received in revised from 29 April 2021;

Accepted 29 April 2021;

Available online 30 April 2021;
}

Biochar and activated carbon are used to adsorb heavy metals such as lead, cadmium, nickel, and some notable organic contaminants that contaminated soils which harmful to human and other living organism (Ameloot, et al., 2013, Adebisi, et al., 2017, Ahmed and Theydan, 2012). Both biochar and activated carbon also has been used as an adsorbent for the removal of cationic dyes, methylene blue and Rhodamine B from aqueous solutions (Bordoloi, et al., 2017, Ahmed and Dhedan, 2012, Foo and Hameed, 2010).

It has been reported that there are about 10,000 different commercial dyes available and over $7 \times 105$ tones of synthetic dyes produced annually world-wide (Foo and Hameed, 2010). It is estimated that $10-15 \%$ of the dyes are lost in the effluent during the dyeing processes (Mahamad, et al., 2015). Improper treatment of dyes in wastewater will cause visible pollution, limiting the penetration of light into the water body (Kumar, et al., 2011, Ong, et al.) as well as the potential mutagenic and carcinogenic effects (Padhi, 2012). Methylene blue (MB) is a cationic dye with chemical formula of C16H18ClN3S and has wide application in textile, paper, plastics, pharmaceutical, food and cosmetics industries. They are considered more toxic than the anionic dyes, because they can easily interact with the negatively charged surface of cell membranes, and can enter into the cells (Orfanos, et al., 2016). MB can cause eye burns which may be responsible for permanent injury to the eyes of human and animals. On inhalation, it can give rise to short periods of rapid or difficult breathing while ingestion through the mouth produces a burning sensation and may cause nausea, vomiting, profuse sweating, and mental confusion (Ahmed and Dhedan, 2012). Therefore, the treatment of wastewater containing $\mathrm{MB}$ is of interest due to its harmful impacts on receiving waters. 
The conventional methods for the treatment of coloured wastewater are physical, chemical and biological treatments. However, there are drawbacks for these technologies. At large scale, most of these conventional methods are not applicable because of the high cost and disposal problems as large amount of sludge is been generated at the end of the process (Ghoreishi and Haghighi, 2003). Among all of these methods adsorption has been preferred due to its cheapness and the high-quality of the treated effluents especially for well-designed sorption processes (Qadeer, 2007). Adsorption is a very effective separation technique in terms of initial cost, simplicity of design, ease of operation and insensitive to toxic substances (Pathania, et al., 2017). Biochar and activated carbon have large surface area, charged surface, and functional groups, hence it is well functioned in waste water treatment by adsorbing heavy metal and organic contaminants (Ameloot, et al., 2013, Shan, et al., 2020). There are many commercial activated carbons in the market, however the precursor for commercial activated carbon is coal which is relative high cost and non-renewable has limited its wide application. Therefore, researchers are finding alternative way to produce activated carbon from agricultural waste and industrial waste (Foo and Hameed, 2010). Biomass waste materials offer an inexpensive and renewable additional source of activated carbon (Sharath, et al., 2017, Ahmida, et al., 2015, Bordoloi, et al., 2017, Mahamad, et al., 2015). These waste materials have little or no economic value and often present a disposal problem and their conversion into activated carbon would add economic value, help reduce the cost of waste disposal and most importantly provide a potentially inexpensive alternative to the existing commercial activated carbons (Rafatullah, et al., 2010).

In this study, pineapple waste biomass (leaves, stem) was used to produce biochar and activated carbon which can be used in adsorption process of methylene blue dye. The pyrolysis process was conducted to produce the biochar, while activated carbon was pretreated by chemical and physically activated by pyrolysis process. The physical and chemical characteristics of biochar and activated carbon are determined to evaluate the adsorption properties.

\section{Materials and methods}

\subsection{Sampling and preparation of pineapple waste biomass (PWB)}

In this experiment, pineapple waste biomass (PWB) was collected at Alor Bukit, Pekan Nanas, Johor. The part of pineapple used in this experiment was stem of Josapine. The sample was washed thoroughly using tap water to remove any impurities prior to drying in an oven (Memmert UFB-400, Memmert AG) at $105^{\circ} \mathrm{C}$ for 24 hours. The dried sample was sent to Biotech Noh Resources, Bandar Penawar to grind into size of 2-5 mm. Finally, the resulting product was stored in air-tight container for further use.

\subsection{Proximate analysis of PWB}

Proximate analysis included the analysis of moisture and ash was carried out according to the methods by American Society for Testing Material (ASTM). The moisture content was analysed according to ASTM D2867 in triplicate as follows; a pre-dried aluminium foil weighing dish was weighed accurately to the nearest $0.1 \mathrm{mg}$. Then, the sample was mixed thoroughly and weighed out 3 to $10 \mathrm{~g}$, to the nearest $0.1 \mathrm{mg}$. Next, the sample was placed into a convection oven at $105 \pm 2{ }^{\circ} \mathrm{C}$ and dried overnight to constant weight $( \pm 0.1 \%$ change in the amount of moisture present upon one hour of reheating). The sample was removed from the oven and placed in a desiccator to be cooled to room temperature. The dish containing the oven-dried sample was weighed to the nearest $0.1 \mathrm{mg}$. The average percentage of moisture on a $105^{\circ} \mathrm{C}$ dry weight basis was calculated as equation:

$$
M \%=\left[\frac{W_{d d}-W_{d}}{W_{0}}\right] \times 100 \%
$$

with $\mathrm{M}$ is moisture (\%), Wdd is weight dry sample plus dish, Wd is weight dish, and Wo is weight sample as received.

The analysis for ash content was carried out according to ASTM D2866 as follows; the samples were dried at $105^{\circ} \mathrm{C}$ and were ground or milled to reduce the size of the large pieces to less than $1 \mathrm{~mm}$ in diameter. The sample was then re-dried at $105^{\circ} \mathrm{C}$ and stored in a desiccator prior to testing. A crucible was placed in a muffle furnace igniting at $575 \pm 25^{\circ} \mathrm{C}$ until constant weight was obtained. The crucible was removed from furnace, cooled to room temperature in a desiccator and weighed to the nearest $0.1 \mathrm{mg}$ and this weight was recorded as the tare weight. The crucible was kept in a desiccator until used. Approximately 0.5 to $1.0 \mathrm{~g}$ of sample was weighed to the nearest $0.1 \mathrm{mg}$ in the tared crucible. The weight of sample was recorded as the initial weight of the test specimen, W2. The container and contents were placed in the muffle furnace and ignited at $575 \pm 25^{\circ} \mathrm{C}$ for a minimum of three hours, or until all the carbon is eliminated. The crucible with its content was removed to a desiccator, cooled to room temperature, weighed to the nearest $0.1 \mathrm{mg}$ and the weight was recorded. The heating process was repeated for one-hour periods until the weight after cooling was constant to within $0.3 \mathrm{mg}$. The final weight of the ash, W1, was recorded. The percentage of ash was calculated, based on the initial weight of the test specimen, as follows:

$$
A \%=\left[\frac{W_{1}}{W_{2}}\right] \times 100 \%
$$

with $\mathrm{A}$ is percentage of ash (\%), W1 is weight of ash, and W2 is initial weight of $105^{\circ} \mathrm{C}$ dried sample.

\subsection{Preparation of adsorbent}

\subsubsection{Preparation of biochar (BC)}

Pyrolysis process at $340{ }^{\circ} \mathrm{C}$ was carried out in Constance FN1000 series heat furnace for 3 hours in order to turn dried PWB to biochar (BC) (Leng, et al., 2014). The biochar was cooled to room temperature and kept in an air-tight container for further use. When it was needed to be used, it was dried at $105^{\circ} \mathrm{C}$ for 24 hours, cooled to room temperature and placed in a desiccator to remove moisture.

\subsubsection{Preparation of activated carbon (AC)}

The ACs were prepared through the chemical activation method as follows (Mahamad, et al., 2015); dried PWB was transferred into a $500 \mathrm{ml}$ beaker containing zinc chloride, $\mathrm{ZnCl} 2$ (activation agent, $136.28 \mathrm{~g} / \mathrm{mol}$, AR grade, QRëC) with a ratio of 1:1 (pineapple waste biomass: $\mathrm{ZnCl} 2$ ) in gram. Next, water was added and it was left to immerse for 24 hours at room temperature with occasional stirring using a glass rod. It was then dried at $110^{\circ} \mathrm{C}$ for 24 hours followed by carbonization at $500{ }^{\circ} \mathrm{C}$ for 1 hour (Constance FN-1000 series heat furnace). After cooling to room temperature, the carbonized sample was washed with warm distilled water $\left(30-35^{\circ} \mathrm{C}\right)$ to remove residual $\mathrm{ZnCl} 2$, filtered and dried at $100{ }^{\circ} \mathrm{C}$ for 24 hours prior to further use.

\subsection{Characterization of adsorbent}

\subsubsection{Brunauer Emmet Teller (BET) analysis}

The surface area of the PWB, AC and BC were determined using a Surface Area Analyzer (ASAP 2020, V3.04H; Micromeritics) through nitrogen adsorption desorption isotherm at $77 \mathrm{~K}$. The Brunauer Emmet Teller (BET) model was applied to determine the total surface area $\left(\mathrm{m}^{2} / \mathrm{g}\right)$ whereas micropore and mesopore area were determined from $\mathrm{t}$-plot analysis. Pore volume was determined from Barret Joyner Halenda (BJH). 


\subsubsection{Fourier Transform Infrared (FTIR) analysis}

Functional groups on the surface of the PWB, BC and AC were identified using the Fourier Transform Infrared analysis (FTIR) where samples were grounded with $\mathrm{KBr}$ (spectroscopic grade) with a ratio of 1:100 (sample: $\mathrm{KBr}$ ) in a mortar before pressed into a 10 $\mathrm{mm}$ diameter disks under 6 tonnes of pressure prior to analysis. The analysis condition used was 16 scans at a resolution of $4 \mathrm{~cm}^{-1}$ measured between 400 and $4000 \mathrm{~cm}^{-1}$ (Mahamad, et al., 2015).

\subsubsection{Scanning Electron Microscopy (SEM)}

The prepared AC and BC were also determined for its morphological characteristics using a JSM 6380 Scanning Electron Microscope (SEM) at the Faculty of Mechanical Engineering, Universiti Teknologi Malaysia (UTM). The samples were mounted onto a SEM holder with double sided electrically conducting carbon adhesive tabs, followed by coating with a $20 \mathrm{~nm}$ thick layer of gold prior to viewing under the electron microscope (Mahamad, et al., 2015).

\subsection{Methylene blue adsorption study}

\subsubsection{Preparation of methylene blue stock solution}

Methylene blue (MB) stock solution, $1000 \mathrm{mg} / \mathrm{L}$ was prepared by dissolving $1 \mathrm{~g}$ of methylene blue, (CH3)2NC6H2(SN)C6H3(CH3)2Cl (MW=373.88 g/mol, HmbG Chemicals) in $1 \mathrm{~L}$ of distilled water. The stock solution was then kept in a dark surrounding at room temperature prior to use.

\subsubsection{Kinetic adsorption experiment}

Kinetic studies were carried out to effect of time on the adsorption process and to quantify the adsorption rate. The aim of kinetic study was to determine the contact time to reach equilibrium adsorption. The amount of MB adsorbed at contact time $\mathrm{t}(\mathrm{min}), \mathrm{qt}$ (mg/g), was calculated using the equation below:

$$
Q_{t}=\frac{\left(C_{0}-C_{t}\right) V}{W}
$$

with qt is amount of MB adsorbed at time t, Co is the concentration of $\mathrm{MB}$ at initial $(\mathrm{mg} / \mathrm{L}), \mathrm{Ct}$ is the concentration of MB at time $\mathrm{t}$ $(\mathrm{mg} / \mathrm{L}), \mathrm{V}$ is the total volume of the solution $(\mathrm{L})$, and $\mathrm{W}$ is the mass of adsorbent (g).

\subsubsection{Effect of MB initial concentration and contact time}

$0.5 \mathrm{~g}$ of the prepared $\mathrm{AC}, \mathrm{BC}$ and commercial AC were added into a series of $250 \mathrm{~mL}$ Erlenmeyer flasks containing $70 \mathrm{~mL}$ solutions of $5-400 \mathrm{mg} / \mathrm{L}$ of MB solution prepared from serial dilution of the MB stock solution $(0.35-28 \mathrm{~mL})$. The mixtures were then shaken at 100 rpm for 12 hours in an orbital shaker (Certomat-R, B.Braun) without any $\mathrm{pH}$ adjustment. $2 \mathrm{~mL}$ of solution was taken for time intervals of $5 \mathrm{~min}, 10 \mathrm{~min}, 15 \mathrm{~min}, 20 \mathrm{~min}, 30 \mathrm{~min}, 45 \mathrm{~min}, 60 \mathrm{~min}$, $2 \mathrm{~h}, 6 \mathrm{~h}$ and $12 \mathrm{~h}$. The concentration of MB was measured using UV-vis spectrophotometer (Lambda 45, Perkin Elmer) at $660 \mathrm{~nm}$ wavelength (Mahamad, et al., 2015).

\subsubsection{Equilibrium adsorption experiment}

Batch equilibrium studies focused on two different parameters which were effect of adsorbent dosage and temperature on $\mathrm{MB}$ adsorption at $1 \mathrm{~h}$ which was the equilibrium time based on kinetic study. The extent of MB removal by adsorbent at equilibrium condition was calculated using typical mass balance correlation as shown in the following equation:

$$
Q_{e}=\frac{\left(C_{0}-C_{t}\right) V}{W}
$$

with qe is extend of MB removal at equilibrium, Co is the concentration of $\mathrm{MB}$ at initial $(\mathrm{mg} / \mathrm{L}), \mathrm{Ce}$ is the concentration of $\mathrm{MB}$ at equilibrium $(\mathrm{mg} / \mathrm{L}), \mathrm{V}$ is the total volume of the solution $(\mathrm{L})$, and $\mathrm{W}$ is the mass of adsorbent $(\mathrm{g})$

\subsubsection{Effect of adsorbent dosage}

0.1-0.5 g of AC and BC were added into a series of $250 \mathrm{~mL}$ Erlenmeyer flasks containing $50 \mathrm{~mL}$ of $400 \mathrm{mg} / \mathrm{L}$ of MB solution at 27 ${ }^{\circ} \mathrm{C}$. Without $\mathrm{pH}$ adjustment, the mixtures were agitated at $100 \mathrm{rpm}$ for $1 \mathrm{~h}$, followed by determination of residual MB concentration at OD660 (Lambda 45, Perkin Elmer) (Mahamad, et al., 2015).

\subsubsection{Effect of temperature}

The effect of temperature on the removal of MB was analysed at temperatures of $30,40,50$ and $60^{\circ} \mathrm{C} .50 \mathrm{~mL}$ of $\mathrm{MB}$ solution with fixed initial concentration of $400 \mathrm{mg} / \mathrm{L}$ was taken in a stoppered conical flask and was agitated with $0.50 \mathrm{~g}$ of $\mathrm{AC}$ and $\mathrm{BC}$. The samples were then placed in an incubator shaker operated at $30-60{ }^{\circ} \mathrm{C}$ and $100 \mathrm{rpm}$ for 1 hour. After that, the concentration of $\mathrm{MB}$ was determined at OD660 (Lambda 45, Perkin Elmer).

\section{Results and discussion}

\subsection{Proximate analysis of PWB}

Table 1 showed the results of proximate analysis of PWB, AC and $\mathrm{BC}$ produced. The moisture content of $\mathrm{PWB}$ was reduced from $18.56 \%$ to $12.22 \%$ and $7.31 \%$ respectively. The moisture content was lost during furnace pyrolysis. AC showed higher moisture content then $\mathrm{BC}$, which could be resulted from the use of $\mathrm{ZnCl} 2$ which was readily hygroscopic. However, ash content of PWB has increased from $6.75 \%$ to $42.39 \%$ and $60.65 \%$ respectively. This was due to the carbonization resulted in the conversion of some carbonaceous materials into ash. AC with low ash content was more preferable to be employed for adsorption processes as high of ash content would interfere with carbon adsorption through competitive adsorption as well as being the catalysis of adverse reactions (Leng, et al., 2014).

Table 1 Data of proximate analysis on PWB, AC and BC

\begin{tabular}{lllc}
\hline Proximate analysis & PWB & AC & BC \\
\hline Moisture (\%) & 18.56 & 12.22 & 7.31 \\
Ash (\%) & 6.75 & 42.39 & 60.65 \\
\hline
\end{tabular}

\subsection{Characterization of adsorbent}

\subsubsection{Brunauer emmet teller (BET) analysis}




\begin{tabular}{|c|c|c|c|c|}
\hline & PWB & $\mathrm{BC}$ & $\mathrm{AC}$ & Commercial AC (Zaini et al., 2013) \\
\hline $\begin{array}{l}\text { Total surface area BET } \\
\left(\mathrm{m}^{2} / \mathrm{g}\right)\end{array}$ & 8.2573 & 56.3824 & 284.1989 & 909 \\
\hline $\begin{array}{l}\text { Micropore surface area } \\
\left(\mathrm{m}^{2} / \mathrm{g}\right)\end{array}$ & NA & NA & 237.162 & 748 \\
\hline $\begin{array}{l}\text { Mesopore surface area } \\
\left(\mathrm{m}^{2} / \mathrm{g}\right)\end{array}$ & NA & NA & 47.0369 & 161 \\
\hline Total pore volume (cc/g) & NA & NA & 0.1668 & 0.442 \\
\hline Micropore volume (cc/g) & NA & NA & 0.0842 & 0.347 \\
\hline Mesopore volume (cc/g) & NA & NA & 0.0826 & 0.095 \\
\hline
\end{tabular}

From Table 2, it can be concluded that commercial AC possesses the largest total surface area, micropore surface, mesopore surface and total pore volume followed by AC. The differences were significant due to low carbon content and high ash content of the precursor which was PWB. However, AC showed higher total surface area than $\mathrm{BC}$ and $\mathrm{PWB}$. This was due to the effect of $\mathrm{ZnCl} 2$ used in the activation process. The $\mathrm{ZnCl} 2$ was expected to increase the micropore volume due to its dehydrating effect, thus providing larger surface area (Mahamad, et al., 2015). Increase of micropore and mesopore surface will lead to the increase of total surface area which was better for adsorption because the adsorbates can diffuse and be trapped in the pores. Therefore, adsorbent with higher porous structure can trap more adsorbate molecules. In this case, MB molecule with diameter of $0.8 \mathrm{~nm}$ will be adsorbed to pores with diameter larger than $1.5 \mathrm{~nm}$, so mesopore was crucial in the adsorption process. There were no micropore and mesopore detected in PWB and BC, however the total surface area of BC was higher than PWB.

\subsubsection{Fourier transform infrared (FTIR) analysis}

Table 3 Functional groups present in PWB, AC, BC, AC-MB and

\begin{tabular}{|c|c|c|c|c|c|c|}
\hline $\begin{array}{l}\text { Wav } \\
\text { enumber } \\
\left(\mathrm{cm}^{1}\right)\end{array}$ & $\begin{array}{l}\text { Functi } \\
\text { onal } \\
\text { group }\end{array}$ & PWB & $\mathrm{AC}$ & $\mathrm{BC}$ & $\begin{array}{l}\text { AC- } \\
\text { MB }\end{array}$ & $\begin{array}{l}\text { BC- } \\
\text { MB }\end{array}$ \\
\hline $\begin{array}{l}3200- \\
3600\end{array}$ & $\begin{array}{l}-\mathrm{OH} \\
\text { alco- } \\
\text { hol }\end{array}$ & I & I & I & & \\
\hline $\begin{array}{l}2950- \\
2840\end{array}$ & $-\mathrm{C}-\mathrm{H}$ & I & & & & \\
\hline $\begin{array}{l}1650- \\
1580\end{array}$ & $-\mathrm{N}-\mathrm{H}$ & I & & & & \\
\hline $\begin{array}{l}1550- \\
1500\end{array}$ & $-\mathrm{N}-\mathrm{O}$ & I & & & & \\
\hline $1440-$ & $-\mathrm{OH}$ & I & & & & \\
\hline 1395 & $\begin{array}{l}\text { car- } \\
\text { boxylic } \\
\text { acid }\end{array}$ & & & & & \\
\hline $\begin{array}{l}1250- \\
1050\end{array}$ & $\begin{array}{l}-\mathrm{C}-\mathrm{O}- \\
\mathrm{C}\end{array}$ & I & & & & \\
\hline $\begin{array}{l}1250- \\
1020\end{array}$ & $-\mathrm{C}-\mathrm{N}$ & I & I & I & I & I \\
\hline $\begin{array}{l}800- \\
600\end{array}$ & $-\mathrm{C}-\mathrm{Cl}$ & I & I & I & & \\
\hline
\end{tabular}

Fig. 1 showed that $\mathrm{PWB}$ contained much more functional groups than AC and BC. This indicated that various functional groups present in raw material spectrum disappeared after the carbonization and activation steps. Upon carbonization, the concentration of functional groups on PWB was lower due to the breakdown of complex lignocellulosic matrix into simpler compounds/groups (Mahamad, et al., 2015). This was proved by the disappearance of peaks at $2926 \mathrm{~cm}^{-1}, 1634 \mathrm{~cm}^{-1}$ and $1237 \mathrm{~cm}^{-1}$ which can be assigned to the $\mathrm{C}-\mathrm{H}, \mathrm{N}-\mathrm{H}$ and $\mathrm{C}-\mathrm{O}-\mathrm{C}$ groups. For AC, the peaks observed at $3456 \mathrm{~cm}^{-1}, 1546 \mathrm{~cm}^{-1}, 1040 \mathrm{~cm}^{-1}$ and $687 \mathrm{~cm}^{-1}$ can be at- tributed to $-\mathrm{OH}$ alcohol, $\mathrm{N}-\mathrm{O}, \mathrm{C}-\mathrm{N}$ and $\mathrm{C}-\mathrm{Cl}$ groups respectively. For BC, the peaks located at $3301 \mathrm{~cm}^{-1}, 1429 \mathrm{~cm}^{-1}$ and $1093 \mathrm{~cm}^{-1}$ indicated the presence of $-\mathrm{OH}$ alcohol, $-\mathrm{OH}$ carboxylic acid and $\mathrm{C}-\mathrm{N}$ groups respectively. The functional groups present in the adsorbents were anionic in order to attract cationic MB molecules for the adsorption process to occur. After adsorption, it showed that $-\mathrm{OH}$ groups were greatly reduced. There were only $\mathrm{C}-\mathrm{N}$ and $\mathrm{C}-\mathrm{Cl}$ groups left which represented by $1030 \mathrm{~cm}^{-1}$ and $697 \mathrm{~cm}^{-1}$ peaks. Table 3 showed the summary of presence of functional groups in $\mathrm{PWB}, \mathrm{AC}, \mathrm{BC}, \mathrm{AC}-\mathrm{MB}$ and $\mathrm{BC}-\mathrm{MB}$ represented by each wavenumber.

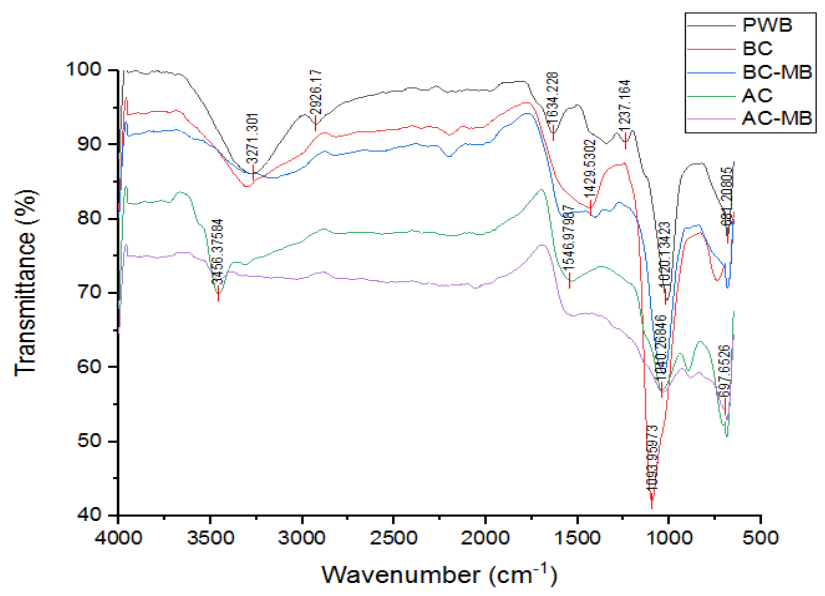

Figure 1 FT-IR spectra of PWB, AC, BC, AC-MB and BC-MB

\subsubsection{Scanning electron microscopy (SEM)}

When comparing the SEM images of the PWB, BC and AC, the changes of surface morphology by activation process were obviously seen (Fig.2). While the raw material has smooth surfaces with no porosity, the surfaces of $\mathrm{BC}$ and $\mathrm{AC}$ have a heterogeneous surface with irregular and randomly distributed pores. The pores were like honeycomb-like structure. However, pore diameter in AC was smaller than $\mathrm{BC}$, the average pore diameter of $\mathrm{AC}$ was found to be was less than $100 \mathrm{~nm}$. Therefore, mesopore and micropore were present in $\mathrm{AC}$ whereas there was only macropore present in BC. This was complementary with the results from BET analysis which stated that AC and BC had higher total surface area than PWB. In all three cases, well-developed porous surface was observed at higher magnification. The same results were reported by other researchers (Mahamad, et al., 2015, Geçgel, et al., 2015, Ghaedi, et al., 2014, Zaini, et al., 2013).
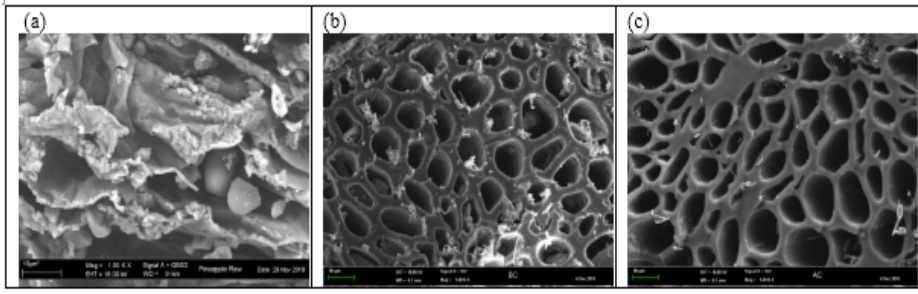

Figure 2 Scanning electron micrograph of (a) PWB, (b) BC and (c) AC (bar represents10 m). 


\subsection{MB adsorption experiments}

\subsubsection{Effect of MB initial concentration and contact time}

Fig. 3 showed the amount of MB adsorbed per unit mass of adsorbent (AC, BC and commercial $\mathrm{AC}$ ) increased with the increase of MB concentration $(5-400 \mathrm{mg} / \mathrm{L})$. The initial MB concentration provided the essential driving force to overcome resistances to the mass transfer of $\mathrm{MB}$ between the aqueous and the solid phases. The higher initial MB concentration enhanced the interaction between the adsorbates and adsorbents. Therefore $400 \mathrm{mg} / \mathrm{L}$ of initial dye concentration had the highest adsorption uptake. The same trend was also reported by other researchers (Mahamad, et al., 2015, Nasuha, et al., 2010). From the graphs plotted, the average time needed to reach equilibrium adsorption was $1 \mathrm{~h}$. This duration was used to conduct equilibrium adsorption experiment with parameters of adsorbent dosage and temperature.

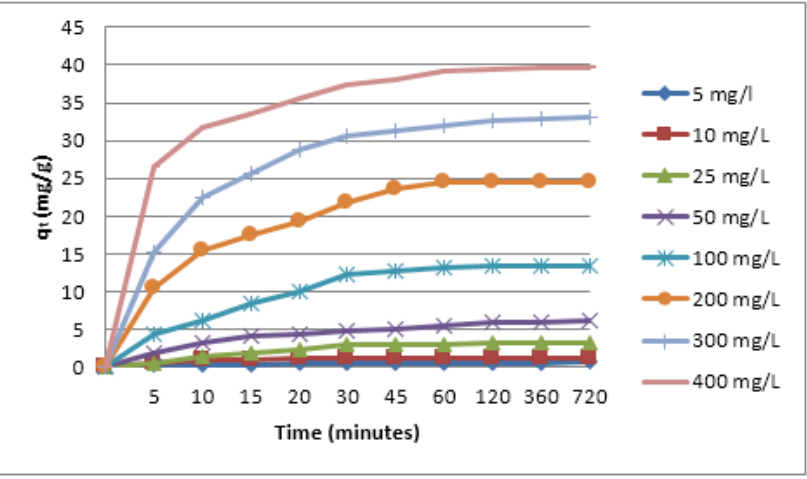

(a)

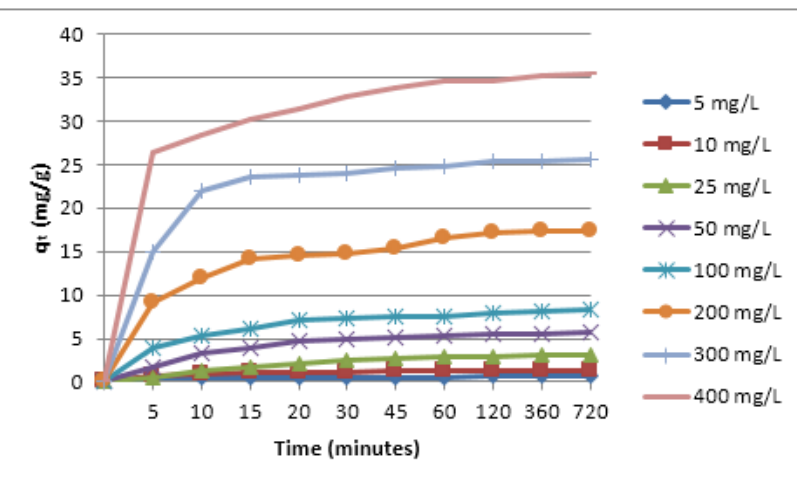

(b)

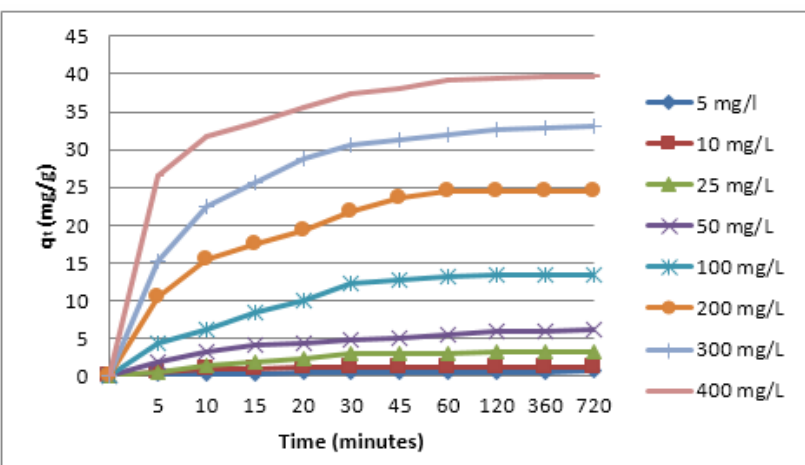

(c)

Figure 3 Removal of $5-400 \mathrm{mg} / \mathrm{L}$ of $\mathrm{MB}$ by $0.5 \mathrm{~g}$ of (a) AC, (b) BC, and (c) commercial AC, within 720 min of contact time.

\subsubsection{Comparison between AC, BC and commercial AC}

In Fig. 4, the equilibrium adsorption capacities for three adsorbents were shown. The data indicated that the highest uptake of $\mathrm{MB}$ at equilibrium time of $1 \mathrm{~h}$ was achieved by commercial $\mathrm{AC}$, followed by AC and BC. These results can be correlated with the surface area of the adsorbents that follows the same trend commercial $\mathrm{AC}>\mathrm{AC}>\mathrm{BC}$. High ash content of AC and BC which interfered with carbon adsorption was also contributed to this result. However, the chemical activation of the biomass to produce the AC greatly enhanced the adsorption capacity which can be comparable with commercial AC.

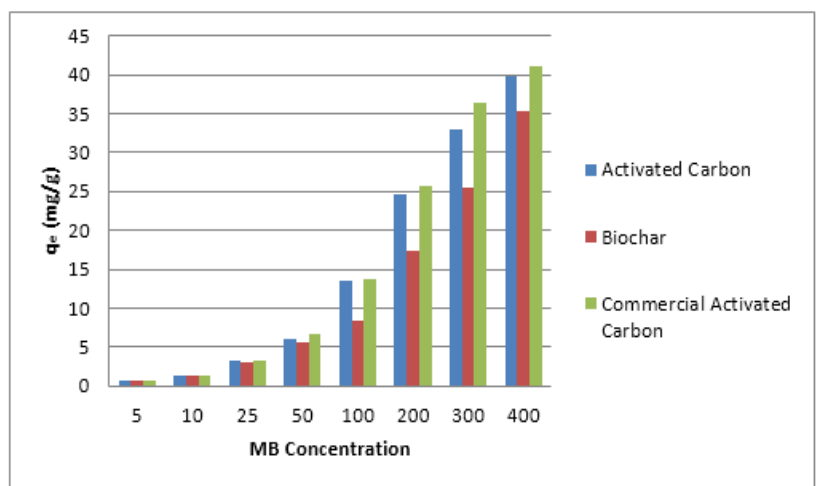

Figure 4 Removal of $5-400 \mathrm{mg} / \mathrm{L}$ MB by $0.5 \mathrm{~g}$ of $\mathrm{AC}$, BC, and commercial AC at $720 \mathrm{~min}$.

\subsubsection{Effect of adsorbent dosage}

Fig. 5 showed that the \% MB removal increased with increase in adsorbent dosage. This was due to the higher availability of active site present for adsorption. However, it did not reach an equilibrium point which represented the maximum \% $\mathrm{MB}$ removal because $0.5 \mathrm{~g}$ was not the optimum amount of adsorbent dosage, more adsorbent dosage should be used to achieve maximum adsorption. After the equilibrium point, the facts of adsorption capacity will decrease with the increase of adsorbent dosage was reported by other researchers (Adebisi, et al., 2017, Krishni, et al., 2014). This was due to the amount of dye adsorbed per unit mass of adsorbent decreased with increasing adsorbent dosage, because of reduction in effective surface area. The adsorbent available was saturated and not fully ultilized at higher adsorbent dosage. This may be also attributed to overlapping or aggregation of adsorption sites resulting in a decrease in total adsorbent surface area available to dye and an increase in diffusion path length.



Figure 5 Removal of $400 \mathrm{mg} / \mathrm{L} \mathrm{MB}$ by 0.1-0.5 $\mathrm{g}$ AC and BC.

\subsubsection{Effect of temperature}

From Fig. 6, the results indicated that the adsorption process was endothermic as the increase in temperature had increased the $\% \mathrm{MB}$ removal by both $\mathrm{AC}$ and $\mathrm{BC}$. This was due to the increase of MB molecules mobility hence facilitated the binding to the active site. An increase of temperature increased the rate of diffusion of the adsorbate molecules across the external boundary layer and within the internal pores of the adsorbent particle, due to decrease in the viscosity of the solution (Nasuha, et al., 2010). 


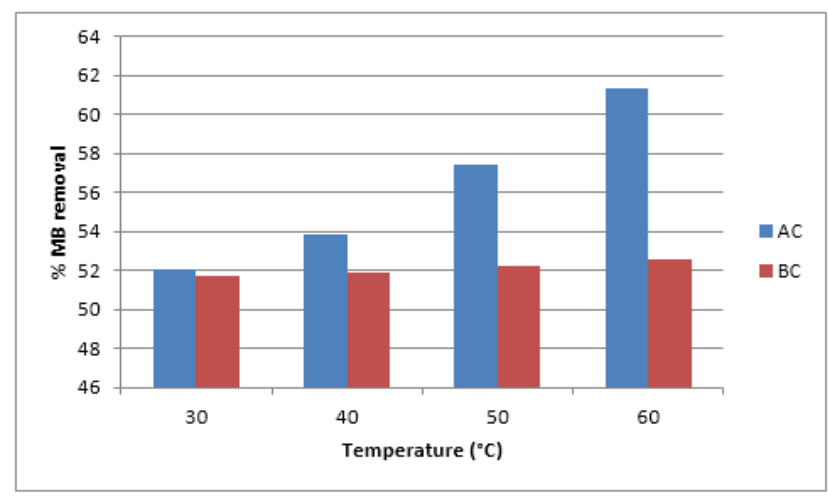

Figure 6 Effect of temperature on removal of $400 \mathrm{mg} / \mathrm{L}$ MB by 0.5 g AC and BC.

\section{Conclusions}

This study has found that PWB showed its potential as sustainable adsorbent alternative for the removal of $\mathrm{MB}$ from wastewater. Furthermore, the adsorption capacity of AC is better than BC produced from PWB is proven in this study. This is due to the presence of porous structure which leads to larger total surface area that provides more functional group binding site to adsorbates and lower ash content. Adsorption of MB by AC and BC increased with the increase of initial concentration of $\mathrm{MB}$ and adsorbent dosage until reached an equilibrium point and high temperature facilitated the adsorption process.

\section{Declaration of competing interest}

The authors declare no known competing interests that could have influenced the work reported in this paper.

\section{Acknowledgements}

The authors thank the Universiti Teknologi Malaysia for facilitating the current work.

\section{References}

K. Jaji, N. Man, N.M. Nawi, 2018. Factors affecting pineapple mar ket supply in Johor, Malaysia, International Food Research Journal, 25, 366-375.

M.F. Zainuddin, S. Rosnah, M.M. Noriznan, I. Dahlan, 2014. Effect of Moisture Content on Physical Properties of Animal Feed Pellets from Pineapple Plant Waste, Agriculture and Agricultural Science Procedia, 2, 224-230.

A. Upadhyay, J.P. Lama, S. Tawata, 2010. Utilization of pineapple waste: a review, Journal of Food Science and Technology Nepal, 6, 10-18.

O.K. Lun, T.B. Wai, L.S. Ling, 2014. Pineapple cannery waste as a potential substrate for microbial biotranformation to produce vanillic acid and vanillin, International Food Research Journal, 21, 953.

M. Tripathi, J.N. Sahu, P. Ganesan, 2016. Effect of process parameters on production of biochar from biomass waste through pyrolysis: A review, Renewable and Sustainable Energy Reviews, 55, 467-481.

D. Sharath, J. EZANA, Z. SHAMIL, 2017. Production of activated car bon from solid waste rice peel (husk) using chemical activation, Journal of Industrial Pollution Control, 33, 1132-1139.

K. Ahmida, M. Darmoon, F. Al-Tohami, M. Erhayem, M. Zidan, 2015. Effect of Physical and Chemical Preparation on Characteristics of Activated Carbon from Agriculture Solid Waste and their Potential Application, International Institute of Chemical, Biological Environmental Engineering June, 5-6.

N. Ameloot, S. De Neve, K. Jegajeevagan, G. Yildiz, D. Buchan,

Y.N. Funkuin, W. Prins, L. Bouckaert, S. Sleutel, 2013. Shortterm $\mathrm{CO} 2$ and $\mathrm{N} 2 \mathrm{O}$ emissions and microbial properties of biochar amended sandy loam soils, Soil Biol. Biochem., 57, 401-410.

G.A. Adebisi, Z.Z. Chowdhury, P.A. Alaba, 2017. Equilibrium, kinetic, and thermodynamic studies of lead ion and zinc ion adsorption from aqueous solution onto activated carbon prepared from palm oil mill effluent, Journal of Cleaner Production, 148, 958-968.

M.J. Ahmed, S.K. Theydan, 2012. Physical and chemical characteri stics of activated carbon prepared by pyrolysis of chemically treated date stones and its ability to adsorb organics, Powder Technol., 229, 237-245.

N. Bordoloi, M.D. Dey, R. Mukhopadhyay, R. Kataki, 2017. ion! Adsorpof Methylene blue and Rhodamine B by using biochar derived from Pongamia glabra seed cover, Water Sci. Technol., 77, 638-646.

M.J. Ahmed, S.K. Dhedan, 2012. Equilibrium isotherms and kinet ics modeling of methylene blue adsorption on agricultural wastes-based activated carbons, Fluid Phase Equilib., 317, 914.

K.Y. Foo, B.H. Hameed, 2010. An overview of dye removal via activated carbon adsorption process, Desalination and Water Treatment, 19, 255-274.

M.N. Mahamad, M.A.A. Zaini, Z.A. Zakaria, 2015. Preparation and characterization of activated carbon from pineapple waste biomass for dye removal, Int. Biodeterior. Biodegrad., 102, 274-280.

P.S. Kumar, S. Ramalingam, K. Sathishkumar, 2011. Removal of methylene blue dye from aqueous solution by activated carbon prepared from cashew nut shell as a new low-cost adsorbent, Korean J. Chem. Eng., 28, 149-155.

S.-T. Ong, S.-T. Ha, P.-S. Keng, C.-K. Lee, Y.-T. Hung, Removal of dyes from wastewaters by low-cost adsorbents, in: Handbook of Environment and Waste Management, pp. 929-977.

B. Padhi, 2012. Pollution due to synthetic dyes toxicity carci nogenicity studies and remediation, International Journal of Environmental Sciences, 3, 940.

A. Orfanos, I. Manariotis, H.K. Karapanagioti, 2016. Sorption of Methylene Blue onto Food Industry Byproducts, in: Editor (Ed.)(Eds.) Book Sorption of Methylene Blue onto Food Industry Byproducts.

S.M. Ghoreishi, R. Haghighi, 2003. Chemical catalytic reaction and biological oxidation for treatment of non-biodegradable textile effluent, Chem. Eng. J., 95, 163-169.

R. Qadeer, 2007. Adsorption behavior of ruthenium ions on act ivated charcoal from nirtic acid medium, Colloids Surf. Physicochem. Eng. Aspects, 293, 217-223.

D. Pathania, S. Sharma, P. Singh, 2017. Removal of methylene blue by adsorption onto activated carbon developed from Ficus carica bast, Arabian Journal of Chemistry, 10, S1445-S1451.

R. Shan, Y. Shi, J. Gu, J. Bi, H. Yuan, B. Luo, Y. Chen, 2020. Aqueous $\mathrm{Cr}(\mathrm{VI})$ removal by biochar derived from waste mangosteen shells: Role of pyrolysis and modification on its absorption process, Journal of Environmental Chemical Engineering, 8, 103885.

M. Rafatullah, O. Sulaiman, R. Hashim, A. Ahmad, 2010. Adsorp tion of methylene blue on low-cost adsorbents: A review, J. Hazard. Mater., 177, 70-80.

L.Y. Leng, A.H.B. Mohd. Hanif, S. Abdul Wahid, 2014. Stability of Pineapple Leaf Residue Chars Generated by Controlled Combustion and by Field Burning in Tropical Peat, CLEAN - Soil, Air, Water, 42, 648-656.

Ü. Geçgel, B. Kocabıyık, O. Üner, 2015. Adsorptive Removal of 
Methylene Blue from Aqueous Solution by the Activated Carbon Obtained from the Fruit of Catalpa bignonioides, Water, Air, Soil Pollut., 226, 238.

M. Ghaedi, A.G. Nasab, S. Khodadoust, M. Rajabi, S. Azizian, 2014. Application of activated carbon as adsorbents for efficient removal of methylene blue: Kinetics and equilibrium study, Journal of Industrial and Engineering Chemistry, 20, 2317-2324.

M.A.A. Zaini, M. Zakaria, S.H. Mohd.-Setapar, M.A. Che-Yunus, 2013. Sludge-adsorbents from palm oil mill effluent for methylene blue removal, Journal of Environmental Chemical Engineering, 1, 1091-1098.

N. Nasuha, B.H. Hameed, A.T.M. Din, 2010. Rejected tea as a pot ential low-cost adsorbent for the removal of methylene blue, J. Hazard. Mater., 175, 126-132.

R.R. Krishni, K.Y. Foo, B.H. Hameed, 2014. Food cannery effluent, pineapple peel as an effective low-cost biosorbent for removing cationic dye from aqueous solutions, Desalination and Water Treatment, 52, 6096-6103. 